\title{
Analysis on the Development and Trend of Third Party Payment
}

\author{
Guangning Pu, Xiu Tang, Yanqi Wang \\ Chengdu Neusoft University, Chengdu, China.
}

\begin{abstract}
Keywords: Third Party Payment; Mobile Payment; Policies and Regulations; Supervision.
\end{abstract}
\begin{abstract}
After more than 15 years of rapid development, the third party payment institutions have become an important supplement to the service market in China. It has been innovated in terms of payment channels and payment tools. It has satisfied the needs of the majority of enterprises and individuals in terms of convenience, real-time and credit guarantee. Thus, it achieved rapid development. In addition, it has changed not only the traditional production mode, but also the consumers' traditional payment habit. And it has become a new growth point of the world economy. This paper will analyze the current situation of the development of third party payment platform in China, and make a comparative analysis of the third party payment between China and the United States, to explore the development trends for third party payment platform in three aspects of supervision, biometrics technologies, and financial technology. At last, some suggestions will be put forward on China third party payment platform to further improve.
\end{abstract}

\section{Introduction}

With the rapid development of e-commerce, the users' stickiness to network consumption is becoming much higher, and online consumption has become a habit to a consumer. At the same time, along with the popularity of mobile devices, mobile payment has covered the various aspects of user's daily life by taking advantages of its convenience and fast speed, including online shopping, traditional shopping, remittance, phone bill, public transportation, personal finance and so on. Among which, online shopping electronic payment activity has led the entire electronic payment market and take above $75 \%$ of the market. In addition to online shopping, people's living payment, recharge services, transfer services, financing services and offline code scanning consumption has also occupied the market to more than 25\% (Shown as Figure 1).

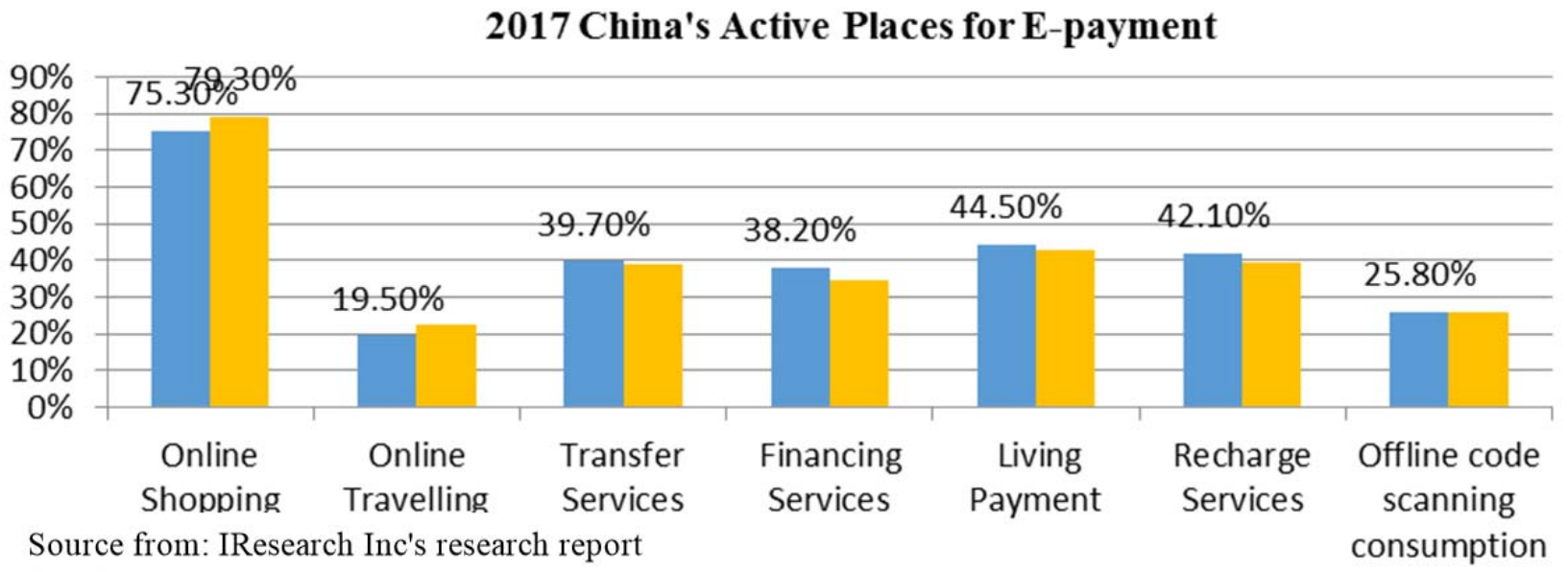

Figure 1 Comparison of active places for electronic payment in China in 2017

The third party payment institutions began to push forward the mobile payment, which brought about a new round of rapid growth of China's third party payment market. According to IResearch Inc's research report (2017) on third party mobile payment industry in China, it indicates that the size of the transaction in 2017 reached 98. 7 billion RMB, and it is also expected to reach 165.9 trillion RMB with the growth rate of 68\% from previous year in 2018. (Shown as Figure 2) 


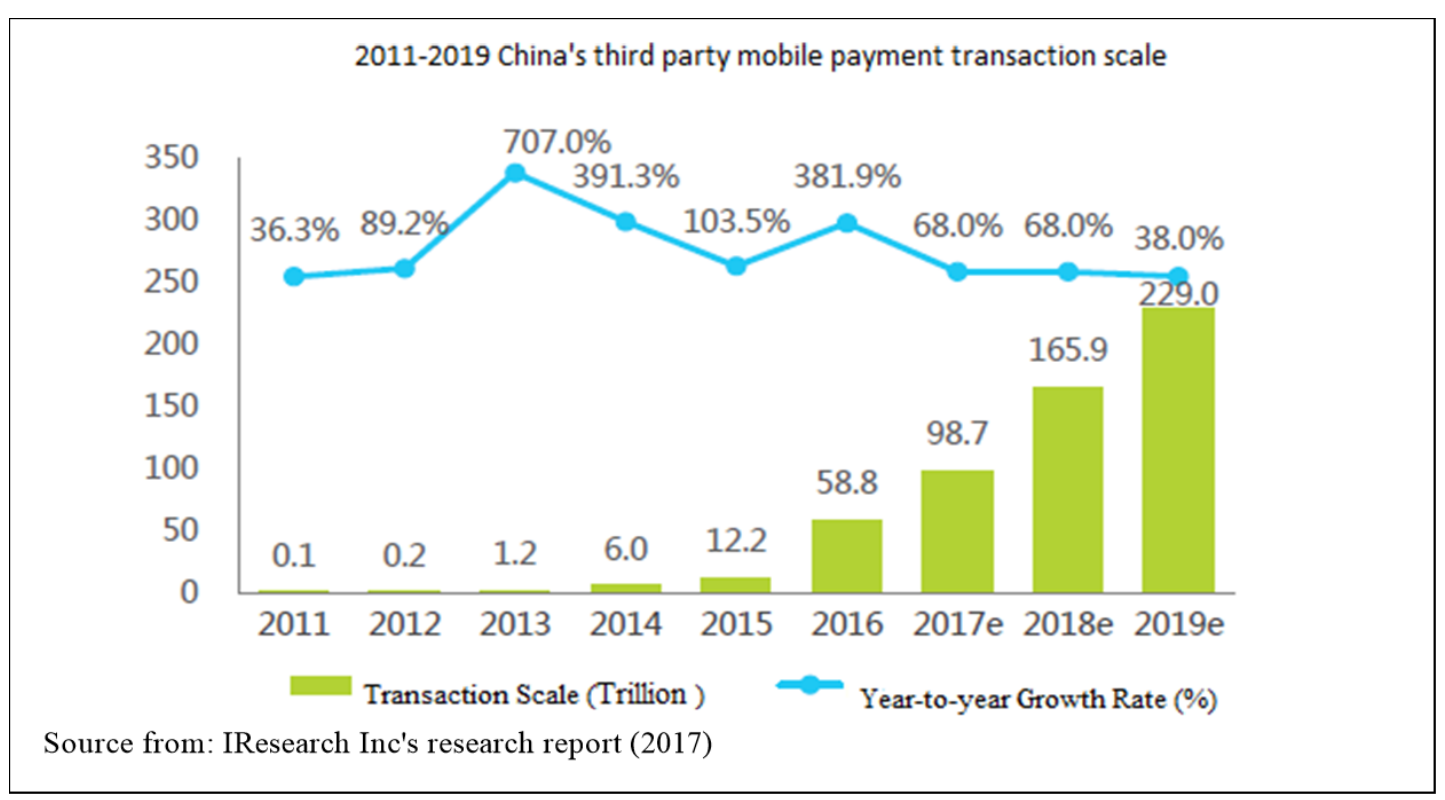

Figure 2 2011-2019 China's third party mobile payment transaction scale

Thus, it can be seen that the size of the third party payment are multiplying. It has penetrated into all aspects of people's life and has a profound impact.

\section{The Present Development of Third Party Payment}

\subsection{The Development History of Third Party Payment and its Laws and Regulations}

In China, third party payment enterprise was born in 1999, and China's third party payment service formally started in 2000. In 2010, online payment of crossing line liquidation system was formally launched. In 2011, Central Bank of China issued the first "payment business license". In the same year, the first batch of payment licenses issued by People's Bank of China, which means the third party payment enterprise is approved by the authority. It indicates that there is a standard to get the access to this industry, and it also help government control the payment market. In 2013, Alibaba launched Yu'e Bao, and users' funds of Alibaba began to transfer to the third party payment platform. In 2014, Tencent launched WeChat's red packet. Under such circumstance, People's Bank of China issued an announcement NO. 6 file "Measures for the Custody of Clients' Reserves of Payment Institutions", which means government started to build supervision and management mechanism from the aspect of clients' reserves of payment to guard against payment risk, and safeguard the legitimate rights and interests for consumers. Since WeChat red packets brought an explosive growth of mobile payments, the People's Bank of China issued the announcement No. 43 [2015] "the Administrative Measures for the Online Payment Business of Non-Banking Payment Institutions” to require the third party accounts to start the real name system and divide the personal payment accounts into category I, II and III. In this way, it can ensure the security of the personal account, maintain the normal economic order, and effectively prevent money laundering and terrorist financing. In 2016, Apple Pay entered into China, WeChat and Alipay started to charge withdrawal fee, and China Union Pay formally issued the "two dimensional code payment standard". In 2017, "Notice of the General Office of the People's Bank of China on Matters concerning Implementing the Centralized Deposit of the Funds of Pending Payments of Clients of Payment Institutions" was issued which indicates the significance of centralizing clients' reserves of payment deposit management for payment institutions: it is to rectify and prevent payment institutions from appropriating and occupying clients' reserves of payment, and urge the third party payment institutions to return to the source of payment business.

On August, 2017, No. 209 was issued by the Central Bank to require payment institutions to complete access to "non-bank payment institutions network payment and settlement platform" and finish business migration preparatory work before October 15, 2017. At present, more than 20 banks and third party payment institutions have completed the access work. In brief, "non-bank payment institutions network payment and settlement platform" is a transfer clearing platform built for third 
party payment institutions. This change means that the direct model has become a history, and relatively independent rules of business regulation for payment and liquidation has come back to the stage. There are six advantages appears from this change, 1 . The platform puts every transfer transaction under supervision, and makes the trading chain become more clear; 2 . It is beneficial for the Central Bank to monitor the flow of social funds in real time; 3. It has reduced the tedious process of docking between the payment institutions and the banks; 4.The rights and responsibilities of the parties which involved in are clearer and independent. 5. It provided more financial data to the Central Bank for supervision. 6. It also provides a relatively equal discourse power to small and medium banks or payment institutions as they want to cooperate with each other.

\subsection{Comparative Analysis of the Third Party Payment Between China and the United States}

In China, The third party payment platform has entered the e-commerce payment field with its good compatibility, credit intermediary, security, convenience. It has quickly occupied most of the market share of online payment. In the business mode, it has third party payment institutions including Aliped and Tenpay as representatives, supply chain finance represented by Taobao and Jingdong, P2P lending platform (which is committed to provide a channel for one who needs financing and who is willing to invest), such as LU.com and Hongling Capital, and crowdfunding (a way that utilize personal goods and stocks to raise funds from public). Now, there is big data finance, representing by Ant Financial Services. The main approach of it is to find new business projects through big data analysis. At the same time, new internet companies and service products can be derived from consumers' daily life needs. For instance, a shared car calls people's attention that to solve the problem of hard to take a taxi when rush hours, as well as the shared bikes to develop urban communications and send people to destination with "the last one kilometer". Again, there are other examples for that, such as third party financial products helping people to invest in financial insurance, and internet financial investment products. And these products are still continuing iterating. Plus, the third party payment has the characteristics of high frequency and strong user perception. Consumers get used to putting their money through these payment tools. Thus, it brings a lot of money to the third party payment platform, as well as builds the bridge between payment tools and financial management (Shown as Figure 4). Since Yu'e Bao launched, the entire financial sector has seen the powerful empowerment of the internet, and the financial products industry are now more accessible than before for companies.

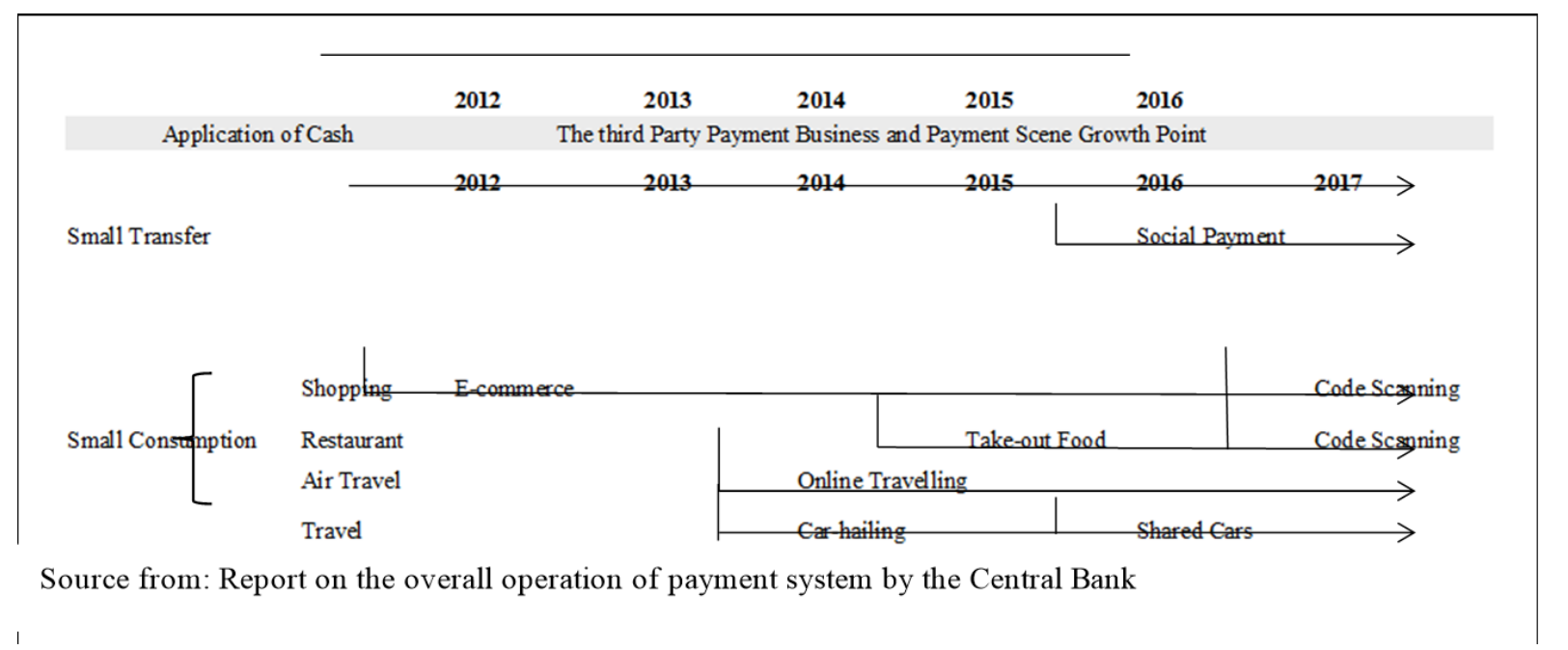

Figure 3 Third party payment business scene growth node diagram

In the United States, the third party payment platform starts early and develops quickly. After years of development, it has a wide range of coverage, taking Pay Pal, the largest online payment provider in the world as an example. It supports trading in more than 190 countries and regions with more than 20 currencies. Once register, users can trade with the sellers in 56 markets all around the world. Meanwhile, the current third party payment institutions in the United States have gradually optimized the system during the process of using, which becomes faster and more convenient. The United States is the first advocate of third party payment services and Internet e-commerce, and is also the largest 
beneficiary in the world. However, the third party payment scene and user activity is still far less than those in China.

The expansion of the third party payment business in China and the United States is closely related to the respective financial characteristics of the two countries. In the United States, the efforts that the traditional financial institutions make to popularize the paperless payment and the attention they pay to attract ordinary users with financial services lead to its third party payment institutions being unable to exceed the traditional financial institutions in the user experience, loyalty and perception. Therefore, it can exist as an auxiliary means of traditional financial institutions. On the contrary, in China, the development of paperless payment popularization is slow. Plus, because of the traditional financial institutions' long-time ignorance of the user experience, and hardly paying attention to the financial needs of the ordinary users, it provides the opportunity for third party payment institutions to grow and even grow fast and independently. As the high frequency of using and high perception function of payment tool, the users will inevitably store a certain amount of money on it. Therefore, the third party payment institutions in China can take the payment function as a breakthrough and surpass the traditional financial institutions in user experience and perception, and can derive more value-added services on the basis of its payment function.

\section{The Development Trend and Suggestion for Third Party Payment}

\subsection{The Development Trend}

\subsubsection{Third Party Supervision Changes From One-Way Behavior to More Sysematic and Standardized System Supervusion}

The regulation of the third party payment industry is not simply a one-way behavior initiated by the government. It should be a process of "governance" involving multiple stakeholders. The payment institutions should comply with the rules of regulation, and keep its bottom lines, reasonably guide the market expectation. At the same time, it should be involved in the formulation of regulatory rules and industry standards, but not just a passive executor. The impact of regulatory factors on the development of the Internet payment market will become more and more important. It plays a crucial role on keeping the sustainable, healthy and stable development of Internet finance.

\subsubsection{Biometrics Will Push and Open a New Round of Cashless Consumption Scenes}

Consumers' needs for convenience of payment scene applications raise new and higher requirements for mobile payments. At present, biometric technology is gradually expanding the attempt on mobile payment. Off-line code scanning payment service is the main force to promote the development of money paper-less society at the present stage. However, biometric payment for security and privacy issues will be the main driving force in the future to promote the development of money paper-less society.

\subsubsection{The Further Development of Financial Technology Has Created a More Secure and Convenient Payment Environment}

The financial innovation brought by technology will be fully applied to the six major financial fields, such as payment and liquidation, loan financing, wealth management, retail banking, insurance, transaction and settlement. With the opening of the industrial chain of mobile payment, financial technology (Fin Tech) will bring each section in the chain into its optimized link. Driven by financial technology, the natural affinity between different technologies will closely connect mobile payment companies to users through biometrics, artificial intelligence (AI), cloud computing and block chain technology. Biometrics enables mobile payment to break through the space constraints and make remote user identification become reality; artificial intelligence makes mobile payment industry pay more attentions on users' experience, loyalty and perceptions; cloud computing makes mobile payment faster and more convenient; block chain makes mobile payment more secure and credible.

\subsection{Policy Recommendations to Promote the Development of Third Party Payments}

\subsubsection{Connect the Credit Data of the Third Party Payment Institutions to the National Credit System}

The third party payment institutions are now outside the financial system. If the credit data of the third party payment institutions are connected with the national credit system, it will better promote 
the improvement of the third party payment credit system. If there is a breach of contract in transaction between buyers and sellers during third party payment, the behavior will be recorded by the system, and then recorded in the corresponding credit reference database, and will be used as a basis for handling other related businesses. Both sides can play the role of restraint. The improvement of the credit data of the third party payment institutions will improve the efficiency of consumers, businesses, platforms and regulators.

\subsubsection{Formulate the Exit Mechanism of the Third Party Payment Institutions, Keep Payment Market Stable and Rationally Allocate Social Resources}

The government should formulate market withdrawal mechanism and stipulate relevant implementation rules and specific operation methods. It should be in accordance with the legal norms of the actual situation of the third party payment market in China. The third party payment institutions can be able to comply with the law when they exit the market. The allocation of social resources should be more reasonable. The third party payment institutions which are unqualified and inappropriate should adopt a reasonable exit method. In the process of withdrawal, the third party payment institutions should be guaranteed rights and benefits, such as their participation in the process of withdrawal, and having chance to express their own opinions, or to be able to make a complaint.

\section{Summary}

In sum, under circumstance of the economic development pattern transformation, China's payment industry, especially the third party payment industry has entered a new stage. Based on its development process this article is of great practical significance to analyze its future development trend. At first, this paper reviews the development process of the third party payment industry in China, expounds the current regulatory and market environment of the industry, and makes a comparative analysis on the third party payment between China and the United States. Then, it makes a judgement of its future development trend that from supervision aspect, the regulation of the third party payment industry is not simply a one-way behavior initiated by the government. It trends to be a process of "governance" involving multiple stakeholders. Biometrics and financial technology innovation will enter the industry and push it to have a significant improvement. At last, suggestions such as connection on credit data of the third party payment institutions with the national credit system, and formulating market exit mechanism to allocate and utilize resources in payment industry are given to put forward on it for further improvement.

\section{References}

[1]. iResearch Inc., 2017. Research Report on China's Third Party Mobile Payment Industry, Dec, 2017.

[2]. iResearch Inc., 2017. 2017 China's Third Party Payment Market Monitoring Report, Dec, 2017.

[3]. Central Bank, 2017. "Report on the Overall Operation of Payment System by the Central Bank," retrieved from: http://www.gov.cn/xinwen/2017-03/15/content_5177588.htm.

[4]. Lee, J., 2017. "Research on the Development of the Third Party Payment Standard in China -Based on the Trend of Internet Financial Development,” Reform and Strategy, 287(33):101-103.

[5]. Zhang, J., 2017. The Development Status, “Potential Problems and Policy Suggestions of China's Third Party Payment,” Science and Technology Economy, 02: 174-175.

[6]. Hou, D.D., 2017. “The Present Situation and Prospect of Third Party Payment in China," Financial Market, 573(7):56-57. 